\title{
Relationship between Health Provider Status and Social Interaction
}

\author{
Bennie Berkeley \\ University of Trinidad and Tobago, Wallerfield, Trinidad and Tobago \\ Email: bennieberkeley8@gmail.com
}

How to cite this paper: Berkeley, B. (2017) Relationship between Health Provider Status and Social Interaction. Open Access Library Journal, 4: e3708.

https://doi.org/10.4236/oalib.1103708

Received: June 5, 2017

Accepted: July 3, 2017

Published: July 6, 2017

Copyright ( 2017 by author and Open Access Library Inc.

This work is licensed under the Creative Commons Attribution International License (CC BY 4.0).

http://creativecommons.org/licenses/by/4.0/

(c) (i) Open Access

\begin{abstract}
This paper proposes a framework for measuring the association or relationship between health provider status and social interaction with patients. It makes two assumptions. The first is that health providers engage in social interaction with patients. The second is that more involved providers have stronger relationships with patients. For example, because doctors have a significant role to play in caring for patients, they should have more interaction with patients than clerks and receptionists. Furthermore, this framework hypothesizes that: 1) health provider status is directly associated with their social interaction; and, 2) the sex of the health provider moderates the strength of this association. This conceptual framework defines three concepts: health provider status, social interaction (ordinal measures), and sex of health providers (a nominal measure). The main limitation is that the theory to be established will be restricted to one independent and one moderator variable and will be appropriate for studying the perspectives of health providers only.
\end{abstract}

\section{Subject Areas}

Public Health

Keywords

Health Provider Status, Sex, Social Interaction

\section{Background and Significance}

\subsection{Background}

Studies on patient satisfaction provide a lens through which health provider and patient interaction could be examined. A simple definition of patient satisfaction is: a patient's attitude towards physicians and medical care. It is the individual's evaluative judgment concerning the quality of medical care received (Hulka, 
Zyzanski, Cassel and Thompson, 1970 [1]). However, their definition does not take account of the health provider's perspective. I contest that the study of a full theory of patient satisfaction must include the health provider perspective.

Primary provider is the main theory used in the study of patient satisfaction. Aragon (2003 [2]) identifies two main factors in patient satisfaction: 1) satisfaction with doctors/surgeons; and, 2) satisfaction with waiting times. In a study of emergency medicine, Guarisco (2008) [3] confirmed that satisfaction with the primary provider and satisfaction with waiting times were critical to patient satisfaction. It is argued that satisfaction with social interaction lies at the heart of patients' satisfaction with primary providers. Asnani (2009 [4]) and Schneider et al. (2004 [5]) point out the significance of physician-patient relationships. Asnani (2009 [4]) argues that patient-physician interaction or communication is significant to good health outcomes. He suggests that communication is the most widely performed procedure in a physician's professional life. However, he bemoans the fact that physicians have not mastered the skill of patient communication. Schneider et al. (2004 [5]) in a study of 554 HIV infected persons, found that better physician-patient relationships produced greater adherence to anti-retroviral treatment.

\subsection{Significance}

The significance of this framework lies in its intention to construct an instrument for measuring health providers' perception of social interaction and the relationship between the status of the health provider and their social interaction (with patients). Moreover, it proposes a hypothesized model that can complement primary provider theory and so produce a full understanding of patient satisfaction. In other words, we will know about patient satisfaction from two perspectives-the patient and the health provider's.

\section{Purpose Statement}

This framework proposes a way health care providers (doctors, dentists and pharmacists) non-medical staff, e.g., nurses and clerical workers) could rate their social interaction with patients. In addition, it proposes that there may be a relationship between the status of health providers and social interaction with patients. In addition, it presupposes that the sex of the health provider moderates this hypothesized relationship. It is not intended to measure patient satisfaction as primary provider theory does. Also, it will support the argument that the study of patient satisfaction must take account of patients' assessment of health providers and health providers' assessment of their interaction with patients. I intend to outline briefly the following issues: influence of patient satisfaction studies, relationship between health provider status and social interaction: a hypothesized model, factors associated with social interaction, conceptualizing social interaction: the dependent variable, conceptualizing sex of health providers: the moderating variable, conceptualizing health provider status: the independent variable, and limitations. The conclusion will summarize succinctly what was 
theorized and suggest the benefit of the framework.

\section{Influence of Patient Satisfaction Studies}

In this paper, it is important to examine patient satisfaction studies. Some research shows that satisfaction with primary providers is about patient satisfaction with interaction or relationships with health providers. The importance of patient satisfaction studies is supported by Thompson-Banko (2009 [6]). She argues that it is significant to understand the customer. He/she should be treated with dignity, respect and concern. She emphasizes that customer service is key to patient satisfaction. However, this framework will not examine some of the factors identified as significant to patient satisfaction. They are health and care products, pharmaceuticals, gift and plant shops and markets for healthy snacks and beverages.

Graham (2009 [7]) states that health providers should be concerned with improving the quality of care delivery and patient safety. He believes that reducing medical errors and waiting times will go a long way toward the creation and maintenance of a leanly managed and organized health system. Graham (2009 [7]) implies that excellent patient care will result in higher levels of patient satisfaction. I reiterate the point that this framework will not consider management of health facilities, medical errors or waiting times.

In Trinidad and Tobago Singh, Mustapha and Haqq (1996 [8]) in a national study of 1500 health center users found that patients expressed high levels of satisfaction with the courtesy and consideration, skills and competence; and advice of doctors, nurses and pharmacists. Satisfaction levels for comfort of health centers and access to health centers were relatively high (73 and 81 percent respectively). In this framework only courtesy will be employed and will be associated with social interaction.

Another study by Joseph and Nichols (2007 [9]) tested eight factors in quality of care at two clinics in South Trinidad. Their major finding was that one third of their sample rated the quality of services and overall clinic experience as unsatisfactory, i.e. some patients were unhappy with communication with staff. On the other hand, Joseph and Nichols (2007 [9]) confirmed that their sample rated the physical conditions of health facilities much higher than communication with staff. It must be emphasized that physical conditions will not be included in this framework.

With regard to the Trinidad and Tobago studies, I make no attempt to evaluate the reliability of findings on patient satisfaction with health providers. This is the case since there are no matched data sets to compare satisfaction levels between 1996 and 2007. Alternatively, I cannot claim that between these years (1996 and 2007) that satisfaction with primary and other health care providers had declined. One comparison that stands out is that satisfaction with physical facilities has remained consistently high i.e. above 50 percent.

In an article, The Anatomy of Poor Health Care, it was stated that ineptitude plagues Trinidad and Tobago's health sector (Rigsby, 2011 [10]). He notes that 
in the country's three major health institutions, innocent lives were snuffed out. His claim was supported by evidence that two mothers and three unborn babies suffered avoidable deaths (Rigsby, 2011 [10]). Similar to the two studies cited, Rigsby's underscores the need for the inclusion of health provider perspective. I argue that health providers should be given the opportunity to reflect on their practice.

\section{Relationship between Health Provider Status and Social Interaction: A Hypothesized Model}

This paper attempts to understand social interaction between health providers and patients from the perspective of the health provider. The framework consists of three variables: an independent variable, a moderator variable and an independent variable. Each variable would be explained in ensuing sections. Figure 1 illustrates that the hypothesized relationship between the independent (health provider status) and dependent (social interaction) variable may be moderated by the sex of health providers.

\section{Factors Associated with Social Interaction}

Joseph and Nichols' (2007 [9]) data collection instrument contained several items for measuring social interaction. Three of their items related to being treated courteously, being greeted and attended to properly and being spoken to positively. Two items sought to determine the extent to which staff (office and nursing) was polite and helpful. One item inquired about the extent to which nurses and physicians explained to patients their illness and treatment options adequately. One question inquired about whether physicians and nurses took enough time to explain adequately what they needed to know and whether their questions were answered thoroughly. Another asked respondents to explain whether the pharmacist, doctor or nurse explained the medication prescribed adequately. Lastly, one item sought to determine whether the receptionist or clerk explained any delay in their care. In this hypothesized model, these items will be modified as follows: interaction before care or treatment, interaction

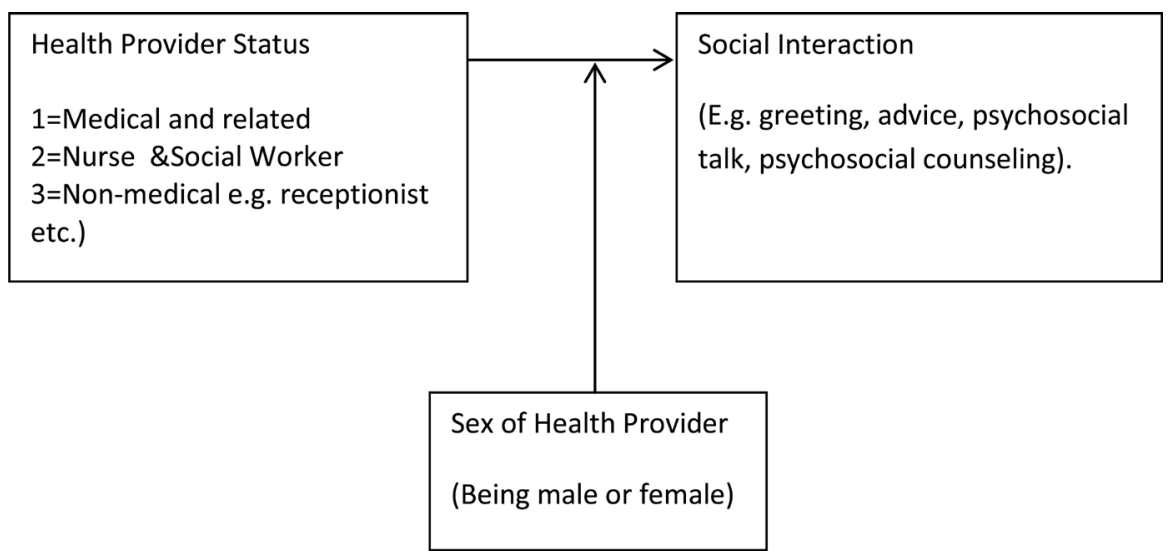

Figure 1. Relationship between health provider status and social interaction: a hypothesized model. 
during care or treatment and interaction after care or treatment.

The significance of the sex of a health care provider in patient care studies is illustrated by Roter, Hall and Aoki (2002 [11]). They found that female biomedical physicians engaged in significantly more active partnership behaviors, more positive talk, more psychosocial counseling, more psychosocial question asking, and more emotionally focused talk. In addition, they noted that females spent two minutes longer with clients than male physicians (Roter, Hall and Aoki, 2002 [11]). These two findings will be used to measure interaction during care.

\section{Conceptualizing the Variables}

\subsection{Conceptualizing Social Interaction: The Dependent Variable}

This conceptual framework proposes a number of issues for measuring social interaction before, during and after patient care. The first three, related to before care, seek to find out whether health providers greet patients politely, whether they explain any delay in care and whether they lead patients to their care hospitably.

Items measuring interaction during care or treatment will require providers to rate the extent to which they treat patients courteously and properly, provide appropriate and adequate information on illness, provide appropriate and adequate advice on treatment including prescribed drugs, provide psychosocial counseling, engage in emotionally focused talk and spend an "appropriate" amount of time with patients. Questions relating to interaction after care will include the following: invited to leave politely, escorted outside the office or facility hospitably and advised to return for follow-up visits. All items will utilize a five point Likert scale where the third choice will be "not applicable".

\subsection{Conceptualizing Sex of Health Providers: The Moderating Variable}

Baron and Kenny (1986 [12]) argue that a moderator variable will influence the direction and or strength of the relationship between an independent variable and a dependent variable. Based on sex differences between medical providers, Roter, Hall and Aoki (2002 [11]), this framework hypothesizes that sex should moderate the relationship between health provider status and social interaction. One question would be used to categorize the sex of a health provider; that is, are you male or female?

\subsection{Conceptualizing Health Provider Status: The Independent Variable}

In this hypothesized model, health provider status is the lone independent variable. It will be measured as a rank-order/ordinal variable such that "medical" will be ranked highest and receptionist/clerk ranked lowest. In other words, providers whose interaction is most significant for effective diagnosis and treatment of patients will be ranked highest. In general, it is expected that receptionists and clerks play little to no role in the direct care and as a result will be ranked lowest. 
I argue that education and training is irrelevant to this rank order. The general rank order is as follows: 1) medical and related providers (doctors, physicians, dentists and pharmacists etc.); 2) nurses and social workers and; 3) non-medical, e.g., ward assistants, receptionists and clerks.

\section{Limitations}

Three significant limitations have been identified. First, there is only one independent variable. However, in this model factors like patient health status and family support will be controlled to minimize their confounding effects on the relationship to be measured. Second, it does not consider factors like physical work conditions and availability of medical technology that may also moderate the strength of association between the independent and dependent variables. Third, since variables are at the nominal and ordinal levels, only non-parametric tests of association like the Spearman's rho and Chi-square can be performed on survey data. In instances when differences between/among provider groups are to be measured, the Mann-Whitney or the Kruskal-Wallis tests will be performed.

\section{Conclusion}

The paper outlines a framework that consists of three main concepts: health provider status, sex and social interaction. The first and the third will be the ordinal measures. The second, sex, will be a nominal variable. Therefore the theory to be developed is limited to association or relationships. However, whenever the moderator test is to be performed, the Adjusted Rank Transformation Test (ART) developed by Leys and Schuman (2010 [13]) should be employed. As an epistemological tool this framework is practical for use among health providers. With the use of data collected by this model, they will be able to reflect on their impact on patient satisfaction, i.e., appreciate that better interaction (communication) with patients will produce better health outcomes and increased patient satisfaction. Data analyzed using this model can be applied to health providers in public and private health institutions. However, when the theory is tested and accepted, it will pave the way for a holistic understanding of patient satisfaction which has been measured from the perspective of patients only. This proclivity is evident in Aragon's (2003 [2]) primary provider theory. The time has come for a complementary theory that marries the perspectives of the patient with those of primary providers.

\section{References}

[1] Hulka, B., Zyzanski, S., Cassel, J. and Thompson, S. (1970) Scale for the Measurement of Attitudes toward Physicians and Medical Care. Medical Care, 8, 429-436.

[2] Aragon, S.J. (2003) Commentary: A Patient-Centered Theory of Satisfaction. American Journal of Medical Quality, 18, 229-241. https://doi.org/10.1177/106286060301800602

[3] Guarisco, J. (2008) Validating the Primary Provider Theory in Emergency Medicine. Leadership in Health Services, 21, 120-130. 
https://doi.org/10.1108/17511870810870565

[4] Asnani, M.R. (2009) Patient Physician Communication. West Indian Medical Journal, 58, 357-361.

[5] Schneider, J., Kaplan, S.H., Greenfield, S., Wenjun, L. and Wilson, I.B. (2004) Better Physician-Patient Relationships Are Associated with Higher Reported Adherence to Antiretroviral Therapy in Patients with HIV Infection. Journal of General Internal Medicine, 19, 1096-1103.

https://www.ncbi.nlm.nih.gov/pmc/articles/PMC1494791 https://doi.org/10.1111/j.1525-1497.2004.30418.x

[6] Thompson-Banko, M. (2009) Beyond the Gift Shop: Boost Revenue, Your Brand, and Patient Satisfaction with Strategic Hospital Retail.

http://hospitalmarketing.blogs.com/my_weblog/2009/07/retail-medicine-.html

[7] Graham, M. (2009) Lean Hospitals: Improving Quality, Patient Safety and Employee Satisfaction. Productivity Press, New York.

[8] Singh, H., Mustapha, N. and Haqq, E.D. (1996) Patient Satisfaction at Health Centres in Trinidad and Tobago. Public Health, 110, 251-255.

https://doi.org/10.1016/S0033-3506(96)80112-0

[9] Joseph, C. and Nichols, S. (2007) Patient Satisfaction and Quality of Life among Persons Attending Chronic Disease Clinics in South Trinidad, West Indies. West Indian Medical Journal, 56, 108-114.

https://doi.org/10.1590/S0043-31442007000200002

[10] Rigsby, D. (2011) The Anatomy of Poor Health Care.

http://www.trinidadexpress.com/letters/The_anatomy_of_poor_health_care-118342 819.html

[11] Roter, D.L., Hall, J.A. and Aoki, Y. (2002) Physician Gender Effects in Medical Communication. The Journal of the American Medical Association, 288, 756-764. https://doi.org/10.1001/jama.288.6.756

[12] Barron, R.M. and Kenny, D.A. (1986) The Moderator-Mediator Variable. A Distinction in Social Psychological Research: Conceptual, Strategic and Statistical Considerations. Journal of Personality and Social Psychology, 51, 1173-1182.

[13] Leys. C. and Schumann, S. (2010) A Non-Parametric Method to Analyze Interactions: The Adjusted Rank Transform Test. Journal of Experimental Social Psychology, 46, 684-688. https://doi.org/10.1016/j.jesp.2010.02.007

Submit or recommend next manuscript to OALib Journal and we will provide best service for you:

- Publication frequency: Monthly

- 9 subject areas of science, technology and medicine

- Fair and rigorous peer-review system

- Fast publication process

- Article promotion in various social networking sites (LinkedIn, Facebook, Twitter, etc.)

- Maximum dissemination of your research work

Submit Your Paper Online: Click Here to Submit

Or Contact service@oalib.com 